\title{
POR UMA GESTÃO DO CUIDADO:PROBLEMATIZAÇÕES ACERCA DA GESTÃO ESCOLAR E SUAS ATUALIZAÇÕES
}

https://orcid.org/0000-0001-5104-8563 Mirele Corrêa ${ }^{\mathrm{A}}$ https://orcid.org/0000-0003-1667’4643 Gicele Maria Cervil ${ }^{\text {B }}$ https://orcid.org/0000-0003-1048-3678 Monique Cristina Francener Hammes Schütz ${ }^{\text {C }}$

${ }^{\text {A }}$ Universidade Estadual de Campinas (Unicamp), Campinas, SP, Brasil

${ }^{\text {B }}$ Universidade Regional de Blumenau (FURB), Blumenau, SC, Brasil

${ }^{\mathrm{C}}$ Universidade Regional de Blumenau (FURB), Blumenau, SC, Brasil

Recebido em: 28 abr. 2021 | Aceito em: 24 ag. 2020 Correspondência: Mirele Corrêa (mirele_correa@yahoo.com.br)

\begin{abstract}
Resumo
Discutir a escola e a gestão escolar é mover-se atento nos fluxos da sociedade de controle, entendendo como os dispositivos de regulação operam nos tempos e espaços, produzindo determinados corpos alinhados a uma certa lógica econômica. O artigo propõe problematizar a escola e a subjetividade do gestor por ela produzida. Busca fazer um exercício genealógico, localizando a invenção da escola na modernidade e atualizações na contemporaneidade. Apresenta as modulações da racionalidade empresarial para a escola, que transforma o diretor em gestor. Envereda-se a traçar possibilidades de ser gestor por meio da ideia de "cuidado de si” desenvolvida por Foucault, como alternativa ao gestor-polícia da escola atual.
\end{abstract}

Palavras-chave: currículo; escola; gestão do cuidado; gestor Polícia.

\begin{abstract}
To discuss the school and school management is to move attentively in the flows of the Control Society, understanding how the regulatory devices operate in times and spaces, producing certain bodies aligned with a certain economic logic. The article proposes to problematize the subjectivities produced by the school, especially the figure of the manager. It seeks to make a genealogical exercise, locating the invention of the school in modernity and its updates in contemporary times. It presents the modulations of business rationality for the school, which turns the director into a manager. It also furthers on plotting possibilities of being a manager through the idea of "self-care" developed by Foucault. A possible alternative to the police manager of the current school.
\end{abstract}

Keywords: care management; curriculum; school; police manager. 


\section{Introdução}

Discutir a escola na atualidade exige estar atento. Os fluxos da sociedade de controle movimentam-se e neles os dispositivos de regulação atualizam-se conforme as exigências econômicas e sociais. Políticas públicas são lançadas tendo por influências os órgãos internacionais e as agendas globais neoconservadoras e neoliberais. Currículos para a educação são produzidos de forma a padronizar o conhecimento e homogeneizar condutas alinhadas a tais políticas, determinando os tempos e espaços da escola e os modos de ser/fazer da gestão.

Tendo em vista este oscilante cenário que configura o campo educacional, a escrita deste artigo propõe três movimentos. Primeiro, localizar a invenção da escola na modernidade, fazendo um breve exercício genealógico das atualizações na contemporaneidade. Segundo, pretende apresentar certas modulações da lógica empresarial/administrativa para escola, destacando a emergência de uma cultura performática que sai do setor privado e invade o setor público. E, por último, evidenciar alguns discursos de gestão democrática que se articulam a esse tempo, produzindo subjetividades cada vez mais responsáveis, ocupadas, polivalentes, participativas, preocupadas com o desempenho, a competitividade e a eficácia, conforme afirma Stephan Ball $(2010 ; 2006)$. Pois, que o objetivo geral do artigo consiste em problematizar a escola e a subjetividade do gestor por ela produzida, figura essa que transita entre a imagem de polícia de si e dos outros (que não necessita mais do corpo ortopédico do diretor disciplinador), mas que também, força o duplo da imagem, buscando na figura do gestor democrático possibilidades de produzir outras coisas.

Diante dessa transição entre a dubiez da imagem, o artigo envereda-se, também, a traçar algumas notas que nos permitem pensar a ideia de "cuidado de si" desenvolvida pelo pensador francês Michel Foucault em seus últimos trabalhos, mais especificamente no curso ministrado no Collège de France em 1982, "A Hermenêutica do Sujeito".

Propor uma "gestão do cuidado" possibilita pensar outros modos de gestão, outras práticas sociais e exercícios próprios de se conduzir no mundo na busca ética pela liberdade e não pela sujeição. Foucault (1984) vai afirmar que o "cuidado de si" implica uma relação complexa com o outro, uma preocupação em fazer o outro cuidar-se de si, "dentro desta perspectiva, o cuidado de si aparece como uma condição pedagógica, ética e, também, ontológica para a constituição do bom governante" (FOUCAULT, 1984, p. 9). 
O gestor, ao cuidar de si, cuida do outro, conduzindo-o a uma formação ético-política, mais humana, mais sensível, mais estética, provendo novas experiências com o tempo presente, com os coletivos, minimizando os efeitos das formações que solapam nossas singularidades e potencializam nossos individualismos e dissensos. Talvez, pensar uma "gestão do cuidado" possibilite uma alternativa à formação que nos homogeneíza, uma fuga às qualificações que nos enquadram em funções estéreis e nos esterilizam.

\section{Da disciplina ao controle: algumas localizações da escola e da gestão escolar}

O momento em que passamos de mecanismos histórico-
rituais de formação de individualidade a mecanismos
científico-disciplinares, em que o normal tomou o lugar
do ancestral, e a medida o lugar do status, substituindo
assim a individualidade do homem memorável pela do
homem calculável, esse momento em que as ciências do
homem se tornaram possíveis, é aquele em que foram
postas em funcionamento uma nova tecnologia do
poder e uma outra anatomia política do corpo. [FOUCAULT, 2010, p. 184]

A escola é uma invenção moderna que não apareceu de súbito, mas reuniu e instrumentalizou uma série de dispositivos que emergiram e se configuraram a partir do século XVI, concebida com o objetivo de atender a um conjunto de demandas específicas da modernidade (VARELA; ALVAREZ-URIA, 1992). Portanto, a escola não existiu sempre e como instituição inventada tem uma finalidade.

A modernidade marca a consolidação de uma nova era social, caracterizada pela urbanização crescente, a estruturação territorial dos estados, novas formas de saber denominadas científicas, o descobrimento de novas terras como a América e a divisão do cristianismo europeu ocidental (DUSSEL; CARUSO, 2003). Devido a tais mudanças, uma nova economia emerge, relações sociais inéditas e novas identidades (como capitalistas e operárias) entram em cena. Com a Revolução Industrial, a Revolução Francesa, o movimento intelectual denominado Iluminismo e a separação entre a Igreja e o Estado, iniciam-se grandes transformações na vida civil, fazendo emergir novas demandas e inseguranças.

As iniciativas de educação popular que, até então, restringiram-se a obras de caridade de caráter privado, "aparecem como a nova ferramenta para a produção em massa da obediência, no contexto de populações que migravam, cidades que cresciam descontroladamente e ritmo de crescimento acelerado" (DUSSEL; CARUSO, 2003, p. 108109). Neste contexto, o poder disciplinar instaura-se para "adestrar as multidões confusas, 
móveis, inúteis de corpos e forças para uma multiplicidade de elementos individuais" (FOUCAULT, 2014, p. 167).

Segundo Foucault (2014, p. 167), o poder disciplinar "é com efeito um poder que, em vez de se apropriar e de retirar, tem como função maior 'adestrar'; ou sem dúvida adestrar para retirar e se apropriar ainda mais e melhor”. O poder disciplinar separa, analisa, diferencia, leva seus processos de decomposição até às singularidades necessárias e suficientes (FOUCAULT, 2014). O poder disciplinar vai intervir incessantemente, desde o primeiro instante, desde o primeiro gesto, desde o primeiro esboço. Tem-se uma tendência de intervir no nível do que acontece, no momento em que a virtualidade está se tornando realidade. O poder disciplinar sempre tende a intervir previamente, antes até do próprio ato, se possível, e isso por meio de um jogo de vigilância, de recompensas, de punições, de pressões, que são infrajudiciárias (FOUCAULT, 2006).

A disciplina "fabrica" indivíduos; ela é a técnica específica de um poder que toma os indivíduos ao mesmo tempo como objetos e como instrumentos de seu exercício. É um poder modesto, desconfiado, que funciona a modo de uma economia calculada, mas permanente. $\mathrm{O}$ sucesso do poder disciplinar deve-se, sem dúvida, ao uso de dispositivos como o olhar hierárquico, a sanção normalizadora e sua combinação num procedimento que lhe é específico: o exame (FOUCAULT, 2014).

Com as primeiras práticas de educação, evidencia-se que o poder disciplinar e suas técnicas foram, pouco a pouco, difundindo-se em larga escala e penetraram a sociedade dos séculos XVI e XVII, tomando no século XVIII a grande forma geral - poder político/corpo individual - (FOUCAULT, 2006) e inventaram as instituições de confinamentos, como a escola. É este contexto “de extensão progressiva dos dispositivos de disciplina ao longo dos séculos XVII e XVIII e sua multiplicação por meio do corpo social" (FOUCAULT, 2014, p 202) que Foucault chamou de sociedade disciplinar e na qual a escola foi inventada. Paralelamente, uma nova estratégia de poder emerge, denominada por Foucault (2008) de biopoder ou biopolítica. É uma estratégia

\footnotetext{
que não exclui a técnica disciplinar, mas que a embute, que a integra, que a modifica parcialmente e que, sobretudo, vai utilizá-la implantando-se de certo modo nela. [...] Essa nova técnica não suprime a técnica disciplinar simplesmente porque é de outro nível, esta noutra escala, tem outra superfície de suporte e é auxiliada por instrumentos totalmente diferentes (FOUCAULT, 1999, p. 288-289).
}

A biopolítica é a maneira pela qual o poder tende a se transformar, entre o fim do século XVIII e o começo do XIX, a fim de governar não somente os indivíduos por meio de 
procedimentos disciplinares, mas toda a população. A população apareceu como objetivo final de governo, para melhorar a sorte, aumentar sua riqueza, sua duração de vida, sua saúde, através de campanhas e técnicas que vão agir indiretamente sobre ela. A população é fim e instrumento de governo. Também será o objeto que o governo deverá levar em consideração em suas observações, em seu saber, para conseguir governar efetivamente de modo racional e planejado (FOUCAULT, 2003).

Com o final da Segunda Guerra Mundial, novos processos de reordenação adquirem consistência. Dentre eles, as tecnologias eletrônicas e digitais, uma organização social baseada no capitalismo mais dinâmico do fim do século XX e início do XXI, regido pelo excesso de produção e pelo consumo exacerbado, pelo marketing e pela publicidade, pelos fluxos financeiros em tempo real e pela interconexão em redes globais de comunicação (SIBILIA, 2012). Para designar esse momento, Gilles Deleuze (1992) utilizou a expressão "sociedade de controle".

[...] é certo que entramos em sociedades de 'controle', que já não são exatamente disciplinares. Foucault é com frequência considerado como o pensador das sociedades de disciplina, e de sua técnica principal, o confinamento (não só o hospital, e a prisão, mas a escola, a fábrica, a caserna). Porém, de fato, ele é um dos primeiros a dizer que as sociedades disciplinares são aquilo que estamos deixando para trás, o que já não somos. Estamos entrando nas sociedades de controle, que funcionam não mais por confinamento, mas por controle contínuo e comunicação instantânea (DELEUZE, 2013 , p. 220, grifos do original).

Deleuze (1992) situou a sociedade de controle como procedente da organização dos grandes meios de confinamento da sociedade disciplinar. Na sociedade de controle, diferente da sociedade disciplinar, o essencial não é mais uma assinatura nem um número, mas uma cifra. A cifra é uma senha, que marca o acesso à informação, ou a rejeição. Não se está mais diante do par massa-indivíduo. Os indivíduos tornaram-se "dividuais", divisíveis, e as massas tornaram-se amostras, dados, mercados ou "bancos". O capital é o que talvez melhor exprima a distinção entre as duas sociedades, pois segundo Deleuze (1992), ele é dirigido para o produto, isto é, para a venda ou para o mercado, e não para a produção. Por isso ele é essencialmente dispersivo.

A fábrica cedeu lugar à empresa. A família, a escola, o exército e a fábrica não são mais espaços analógicos distintos que convergem para um proprietário, Estado ou potência privada, mas são agora figuras cifradas, deformáveis e transformáveis, de uma mesma empresa que só tem gerentes.

Outra característica dessa sociedade é a entronização da empresa como uma instituição modelo que contagia as demais instituições, assim como a escola e os corpos que por ela 
circulam. Propaga-se um culto da performance ou do desempenho individual, que deve ser cada vez mais destacado e eficaz. O comportamento passa a ser medido por critérios de custobenefício e outros parâmetros mercadológicos, que enfatizam a capacidade de diferenciação de cada indivíduo na concorrência com os demais (DELEUZE, 1992). Essa diferenciação individual vai se dar, sobretudo, através das habilidades e competências, que hoje afiguram as propostas curriculares. Laval (2004) vai afirmar que a competência está estreitamente conectada com a exigência de eficácia e de flexibilidade solicitada aos trabalhadores. A competência é aquilo pelo qual o indivíduo é útil na organização produtiva e permite que ele seja reconhecido por aquilo não sancionado pelo diploma ou cursos de capacitação.

Da modernidade até os nossos dias, a escola mantém traços disciplinares, modifica e atualiza as estratégias, aperfeiçoando e inovando as tecnologias e espaços na sociedade de controle (DELEUZE, 1992; CERVI, 2010). Se a escola, tal qual nós a conhecemos, não existiu sempre, as práticas discursivas sobre ela não foram sempre as mesmas. Modulações da empresa para escola, das teorias de administração para as teorias da administração escolar, da crise da administração para a quase extinção do administrador escolar e dele para a reforma pela gestão democrática, demonstram que o diretor/administrador escolar da sociedade disciplinar não cabe mais nessa sociedade, e nela inventa-se o gestor (CERVI, 2013).

A emergência do discurso da gestão democrática, a necessidade da institucionalização da democracia como regime político e ideológico progressista como desejo de todos, e como possibilidade de pensar as escolas públicas mais igualmente e as relações que nelas se constituem de forma mais coletiva, contribuem para a formação/invenção do gestor escolar (CERVI, 2013).

A partir da década de 1980, no Brasil, amplia-se a escola pública e, em meio a duras críticas à ditadura, ao autoritarismo, ao tecnicismo, à falta de liberdade, à autonomia, à necessidade de participação, multiplicam-se as produções sobre a escola e a democracia. Esses discursos começam a adentrar nas escolas e nos cursos de formação de professores (CERVI, 2013).

O discurso sobre democracia também marcou a legislação, em especial a Constituição Federal de 1988 e a Lei de Diretrizes e Bases para a Educação nº 9394 de 1996, e muitos outros documentos produzidos e divulgados pelo Ministério da Educação que vieram depois, como as diretrizes e parâmetros curriculares. As políticas de educação delineavam certa racionalidade para uma escola democrática, provocada por vivências, leituras e documentos. Então, projetase o gestor escolar democrático. 
O governo dos corpos transformou-se em um processo individualizado de gestão e administração do corpo. "E para administração das escolas: gestão democrática. [...] Com o objetivo de tornar invisível, fazer circular, fazer participar, diluir, incluir, descentralizar, responsabilizar, democratizar, controlar e governar" (CERVI, 2013, p. 57). Pois, nesta sociedade denominada por Deleuze (1992, p. 5), sociedade de controle, “o controle é de curto prazo e de rotação rápida, mas também contínuo e ilimitado, ao passo que a disciplina era de longa duração, infinita e descontínua. O homem não é mais o homem confinado, mas o homem endividado".

A passagem da sociedade disciplinar para a de controle anuncia as modulações da passagem do administrador para o gestor, uma passagem em que convivem as conveniências, uma passagem em que uma não elimina a outra, a qualificação marca a sociedade disciplinar, convive com outras e sempre mais qualificações como também convive com as certificações da sociedade de controle. É a passagem do diretor como intelectual condutor da massa, para o divíduo consciente e esclarecido que conduz e se conduz, para a aprendizagem do conduzir-se e conduzir o outro dentro da norma (CERVI, 2013, p. 132, grifo do original).

Ainda segundo Cervi (2013), a escola democrática e a gestão democrática podem ser vistas como dispositivos que articulam a nova utopia de "salvação" da escola. Não se trata de negar a democracia, mas salientar que ela pode funcionar para isso e aquilo. Tanto pode se caracterizar como tempos de construir coletivamente, como pode funcionar como captura, e é aqui que devemos estar atentos.

Numa sociedade que pretende controlar tudo e todos, em que todos são polícias de si e dos outros, a lógica da vigília, dispositivo por excelência da sociedade disciplinar, não some, mas atualiza-se na sociedade de controle camuflando-se na escola, principalmente por meio de um extenso trabalho de ortopedia do corpo em situações de participação, autonomia e exercício do que se aprende por democracia. Uma ortopedia que implica uma imobilização, obediência, submissão, controle, a produção de uma dada racionalidade. São outros nomes que produzem o mesmo, para que a gestão possa estar em sintonia com uma lógica democrática, mas sobretudo, com uma lógica de mercado atendendo ao consumidor, e assegurando direitos e liberdades.

O poder é doravante uma "gestão", o comando é uma "mobilização", a autoridade é uma "ajuda": "dirigir, hoje em dia, não é mais comandar mas motivar; não é mais vigiar mas ajudar; não é mais impor mas convencer; não é mais se perder na complexidade mas delegar". Dirigir é "assegurar um leadership", é "gerenciar", é "animar", e sobretudo é "educar". Este novo estilo de dominação fundamentado no "arrebatamento" e no "coaching" proclama que o tempo do "fim da autoridade" é chegado (LAVAL, 2004, p. 265). 
Esse neogerenciamento, que descentraliza o poder, tirando do gestor a autoridade e a autonomia de tomar decisões, mantém os gestores sempre preocupados e ocupados no mantenimento quase mecanizado de decoros, demandas, expectativas, indicadores, discursos, que vão esvaziando e minimizando a potência de sua figura frente a ação educativa, fazendo questionar sobre as práticas democráticas. Laval (2004) aponta que o neoliberalismo escamoteou a proposta da gestão democrática, fazendo confundir gerenciamento participativo com democracia, "passando da igualdade abstrata à desigualdade assumida" (p. 249), e isso impõe pensar efetivamente que no movimento do cotidiano da escola as propostas se complicam e tendem a vergar em movimentos oscilantes para um ou outro lado, pois não estamos dissociados nem de nossas ideologias e resistências, nem daquilo que nos é imposto enquanto discursos de verdade dentro de um jogo político. Por isso, a próxima seção busca tensionar esse entre deux, e nos colocarmos dentre aquilo que é possível.

\section{Entre deux: a gestão polícia e a gestão do cuidado}

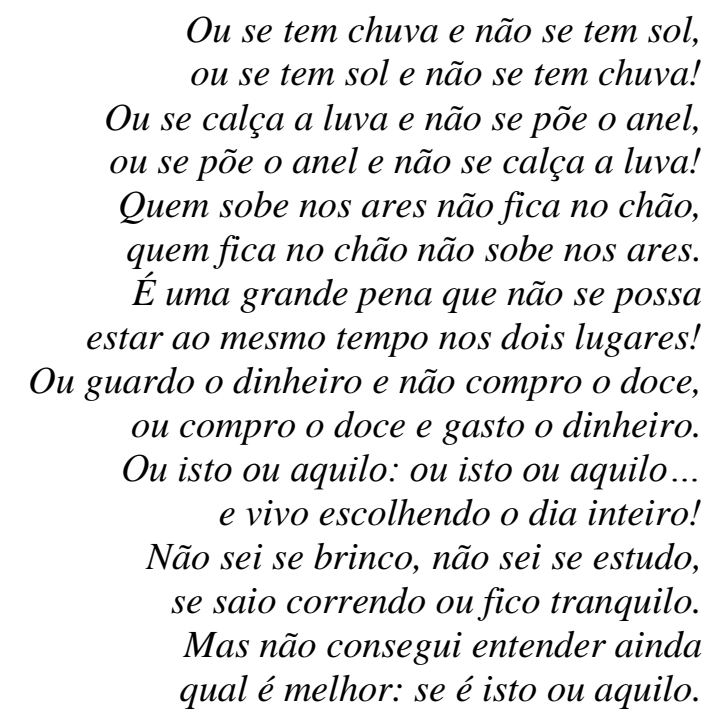

[Cecília Meireles, 1990]

Na seção anterior discutimos a invenção da escola e suas atualizações, bem como destacamos algumas modulações dos discursos sobre gestão. O gestor que vai carregando o corpo disciplinador do diretor, tal-qualmente vai atualizando sua função junto a outras tecnologias que vão aparecendo nesse tempo: a democracia, a participação, a regulação, a tecnologia, a avaliação e a performatividade. 
Conforme o sociólogo inglês Stephen Ball (2003), a performatividade se instaura como uma cultura na medida em que é uma tecnologia e um modo de regulação dos corpos que empregam formas de julgamento, comparações e exposições, tomados respectivamente como meio de controle, de desgaste e de mudança. Na atual sociedade neoliberal, vemos crescer um discurso de poder que se articula por meio da accountability $^{i}$ e da competição. Forjando identidades voltadas a uma lógica do desempenho, conferindo ao conhecimento um valor cada vez mais performático a ser visível e medido.

Diferente do que acontecia na sociedade disciplinar (FOUCAULT, 2014), em que a forma de controle era a potência da vigilância, este novo dispositivo trata-se da incerteza de saber quem é o vigia e "da instabilidade de ser julgado de diferentes maneiras, por diferentes meios, por meio de diferentes agentes" (BALL, 2010, p. 39).

Ball (2006) explica que estas transformações recaem especialmente sobre o setor público, no qual as formas de emprego, as estruturas organizacionais, as culturas e os valores, os sistemas de financiamento, os estilos de administração que faziam parte de um Estado de Bem-estar Social passam para um Estado do Trabalho, substituindo o discurso fordista de produtividade e planejamento por uma retórica de flexibilidade e empreendedorismo pósfordista, contribuindo para uma mudança, também, do poder e controle estatal, que passou a ser exercido por uma tecnologia à distância, pois que nessa sociedade esse poder não se encontra mais centralizado no Estado, ele está capilarizado nas relações.

Onde antes predominava uma economia neotaylorista, focalizada na intensificação dos sistemas de controle direto, o novo gerencialismo do Estado do Trabalho oferece um modelo de organização centrada nas pessoas, permitindo maior produtividade e abertura para o "espírito empreendedor". Esse novo gerencialismo sai do setor privado e invade o setor público, não podendo este ser mais visto com qualidades especiais que o distingam de um negócio, de um mercado ou de um modelo comercial. O setor público, desde o século passado, passa a ser reestruturado e reavaliado por discursos de excelência, efetividade e qualidade, transformando valores e culturas, bem como formando novas subjetividades (CORRÊA, 2017).

$\mathrm{Na}$ escola, esse novo gerencialismo acaba entrando principalmente com vista a reestruturar o segmento dos diretores, desmantelando os regimes organizacionais profissionaisburocráticos e sua substituição por regimes empresariais-mercadológicos (BALL, 2006). As escolas passam a ser submetidas à produção constante de dados sobre si mesmas por meio das avaliações em larga escala, instrumentalizados por organismos internacionais e intergovernamentais (como o FMI, OMC, OCDE, Banco Mundial, Comissão Europeia, 
Unesco, PISA, etc.) e por meio de instrumentos dos mais variados (provas, relatórios, formulários, diagnósticos, PPPs).

Ball (2010, p. 45) ressalta ainda que com essa cultura performática a gestão escolar vai mantendo-se preocupada somente com aquilo que exige o mercado: competição, adequação, eficiência, produção, dados, resultados. Pois, conforme Lopes e Macedo (2006, p. 46), "os melhores currículos são entendidos como os que garantem os melhores desempenhos", logo, assim como empresas do setor privado, a escola deve organizar seu currículo com base nos objetivos comportamentais, a estruturação curricular com base nas competências e o planejamento do currículo com base na divisão de tarefas, engendrando mecanismos de controle tanto dos docentes quanto dos discentes, de forma a garantir a eficiência e a eficácia dos sistemas de ensino (LOPES; MACEDO, 2006).

A gestão democrática, mesmo com sua promessa progressista e conquistando muitos feitos e avanços num campo antes minado por práticas autoritárias, também operou alinhada ao sistema econômico, produzindo o homo oeconomicus neoliberal (FOUCAULT, 2008); isso fez com que nos impulsionássemos a uma era pós-democrática ${ }^{i i}$, na qual " a moralidade foi mercantilizada e os mercados, moralizados" (BROWN, 2019, p. 27), e o que se vê prosperar é um cenário no qual

[...] a ação coletiva se tornou mais difícil, porque os indivíduos são submetidos a um regime de concorrência em todos os níveis. As formas de gestão na empresa, o desemprego e a precariedade, a dívida e a avaliação, são poderosas alavancas de concorrência interindividual e definem novos modos de subjetivação. A polarização entre os que desistem e os que são bem-sucedidos mina a solidariedade e a cidadania. Abstenção eleitoral, dessindicalização, racismo, tudo parece conduzir à destruição das condições do coletivo e, por consequência, ao enfraquecimento da capacidade de agir contra o neoliberalismo (DARDOT; LAVAL, 2016, p. 9).

A descentralização das responsabilidades e a desburocratização da gestão escolar não fizeram crescer em nada a democracia, tal como era previsto. Pelo contrário, borraram e fizeram confundir os níveis de poder do Estado, mesclando-os ao mercado e às agências externas. No fim, o que se quer é transformar a escola numa máquina eficaz da competitividade econômica. E Laval (2004) complementa:

Não é mais a vigilância moral e política sobre os professores que importa, principalmente. Se é preciso aumentar as vigilâncias de detalhe, impor um poder de proximidade, é sobretudo para aumentar a "performance" dos professores e melhor fazê-los servir aos novos objetivos econômicos e sociais da escola (LAVAL, 2004, p. 261).

Revista Interinstitucional Artes de Educar. Rio de Janeiro, V.7, N.2 - pág. 1167-1183 mai-ago de 2021: "Dossiê História das Mulheres e Educação" - DOI: 10.12957/riae.2021.63459 
Diante destes mecanismos de controle e vigilância de uns sobre os outros e de si sobre si mesmo, questiona-se: "como estar aí sem me tornar isso? Como estar aqui sem ter a conduta de polícia?" (CERVI, 2013, p. 189). Sem ter que servir ao mercado? Como não ruir com o que nos sobra de democrático, ainda que exíguo?

Motivadas por estas provocações queremos pensar formas de criar/percorrer um contrafluxo que nos faça romper a linha ou traçar fugas, suspender a função máquina/polícia da gestão articulada a uma forma de governo que nos sujeita a uma condição de vida neoliberal e pensarmos numa função máquina de guerra, como proposto por Deleuze e Guattari em Mille plateaux (1980), capaz de resistir às tecnologias de assujeitamento e, ao mesmo tempo, nos dar uma condição de autoria sobre a vida e sobre os processos de constituição do sujeito que a escola agencia. Resistências em movimento.

Queremos sugerir a tematização da experiência pedagógica com novas cifras, e para tanto nos apoiamos no conceito de "cuidado de si" desenvolvido pelo pensador francês Michel Foucault, como ferramenta para propor uma "gestão do cuidado", enquanto caminho para repensar e praticar a educação de outros modos.

Tal conceito vai aparecer nas últimas obras de Foucault, mais especificamente no curso ministrado ao Collège de France em 1982, “A Hermenêutica do Sujeito"iii. Época esta em que Foucault encontra-se preocupado com os jogos de verdade que vão constituindo o sujeito ao longo de suas relações, buscando um “deslocamento das práticas de governo dos vivos para o governo ético de si mesmo, indagando a potencialidade da noção de cuidado de si na concretização de novas formas de vida para além da genealogia da sujeição" (FREITAS, 2010, p. 169). O pensador faz uma análise genealógica das práticas de si experenciadas pelas civilizações antigas greco-romanas e evidencia "um exercício de si sobre si mesmo através do qual se procura se elaborar, se transformar e atingir um certo modo de ser" (FOUCAULT, 1984, p. 1). Um modo de ser pautado na liberdade como uma ética-política, um cuidado de si apontado como uma potência instituinte imanente à vida. Relendo o aforismo socrático "Conhece-te a ti mesmo" para "cuida-te de ti mesmo", Foucault problematiza a importância de conhecer-se a si para cuidar de si mesmo, o que permite "o conhecimento de um certo número de regras de conduta ou de princípios que são simultaneamente verdades e prescrições. Cuidar de si é se munir dessas verdades: nesse caso a ética se liga ao jogo da verdade" (FOUCAULT, 1984, p. $4)$.

O cuidado de si é uma prática social, uma maneira ativa própria de se conduzir no mundo na busca ética pela liberdade e não pela sujeição, o que implica estabelecer consigo mesmo 
certa relação de domínio, de controle, com vistas a saber o que melhor lhe convém, por meio de quais tomadas de decisões. São práticas sobre si que "vão formar no indivíduo determinadas atitudes ou disposições consideradas necessárias para enfrentar os acontecimentos da existência" (FREITAS, 2010, p. 178). De maneira nenhuma o cuidado de si vincula-se a uma moral cristã de renúncia de si e nem a uma prática narcisista egocêntrica ou hedonista. Do mesmo modo que não é uma resposta às questões do tempo presente, não é a saída, mas, possibilidades de pensar com Foucault (1984) quando afirma que o cuidado de si implica uma relação complexa com o outro. E ainda vai dizer que na Grécia Antiga o filósofo exercia um papel fundamental na política, porque se ocupava com o outro, preocupava-se em conduzi-lo eticamente, "dentro desta perspectiva, o cuidado de si aparece como uma condição pedagógica, ética mas, também, ontológica para a constituição do bom governante" (FOUCAULT, 1984, p. 9).

Podemos fazer um exercício de pensar o gestor na contemporaneidade com as pistas oferecidas por Foucault sobre os filósofos gregos. Nelas, e provocadas por elas, pensamos que o gestor está aí para mobilizar um estranhamento, uma inquietação, para provocar um desassossego, para fazer o seu entorno perceber - e aqui inclui toda a comunidade escolar - que é preciso olhar para si para poder exercer a função de educar o outro. É cuidar de si para cuidar do outro. Práticas que condizem com que Foucault (1984) vai chamar de exercícios de "ser consigo mesmo" ou exercícios de "espiritualidade" tomados pelos estoicos. Tais exercícios permitem alcançar um saber capaz de se relacionar com as coisas que nos cercam. É toda uma disposição corporal, uma atenção com o próprio corpo, um cuidado com a saúde física e mental, um distanciamento dos conflitos e dos desgastes, uma postura de escuta de si e do outro, meditação, um zelo com o uso da palavra, um exame de consciência, um olhar atento para a formação estética, uma disposição para o sensível, para o humano e inumano, para aquilo que nos toca, nos afeta, nos faz um "sujeito da experiência” (LARROSA, 2002).

\footnotetext{
Isso equivale a dizer que o cuidado de si não nos afasta do mundo. Ao dirigir a atenção para si, o que se busca é avaliar o lugar que se ocupa no mundo e o sistema de necessidades no qual o sujeito se encontra vinculado. $\mathrm{O}$ cuidado de si configura-se como um princípio ordenador de nossas ações. Longe de nos isolar da comunidade humana, ele aparece precisamente como um modo de manter nossas ações nos limites e formas consideradas convenientes, ou seja, uma maneira de abordar a formação humana no registro ético (FREITAS, 2010, p. 179).
}

Estrategizar a vida. Prover experiências com aquilo que está aqui no tempo presente de maneira a nos tornar mais leves e sensíveis, talvez, possa ser uma linha de fuga àquela formação 
que solapa nossa singularidade, que dissipa nossos coletivos, que individualiza e minimiza nossas potências criativas, que estimula a competição e o dissenso. Talvez, pensar uma "gestão do cuidado" possibilite uma fuga à formação que nos homogeneíza, uma fuga às qualificações que nos enquadram em funções estéreis e nos esterilizam. Acordando com Freitas (2010, p. 179), “o que está em questão não é revelar/decifrar a verdade do sujeito, mas decidir o que fazer com o que se é e como realizar o que se é. A finalidade é evidenciar formas de exercício da liberdade. Saber, simplesmente, que sempre podemos ser outros; podemos estranhar nossas figuras atuais".

A gestão na escola pode ser muitas coisas: pilhas de papéis, responsabilidades, afetos, pressões por bons resultados nas avalições de larga escala, formação humana, aprendizado, ausência de professores, competição, formação de coletivos, problemas na formação, invenções, falta de recursos financeiros, falta de tempo, falta de estudo, possibilidades, zelo, experiências, inércia, desassossegos, individualismos, cuidado de si e com o outro. A gestão não se resume a um verbo de estado que a torna pequena e fascista. A gestão é multiplicidade, carregada de preposições...e...e...e, está nos fluxos, nos movimentos e nas transições. Portanto, não é isto ou aquilo, supracitando Cecília Meireles (1990), mas é entre isso $e$ aquilo. Um entre que arrasta tudo, que hibridiza as linhas, mescla os fluxos. As linhas estão todas ali, tensionando os dualismos, se complicando, nos colocando de um lado a outro. Cabe a nós criarmos formas de percorrermos fluxos mais transeuntes, mais fugitivos às linhas duras do sistema. Percorrermos fluxos mais criativos e inventivos de vida, fluxos que recuperem práticas de gestão democrática tal qual sonhada. Vida como obra de arte, assim dizia Foucault (1984). Gestão é uma possibilidade de ver a disposição cuidadosa dos objetos. Tal qual nos provoca Souriau (1939) apud Lapoujade (2017, p. 43) no livro "Existências Mínimas",

\footnotetext{
Penso em uma criança que dispôs diversos objetos, grandes e pequenos, cuidadosamente, longamente, de uma maneira que ela achou bonita e ornamental, sobre a mesa de sua mãe, para "agradá-la". A mãe chega. Tranquila, distraída, pega um dos objetos do qual ela vai precisar, recoloca um outro no seu lugar de sempre, e desfaz tudo. E quando as explicações desesperadas que acompanham os soluços contidos da criança lhe revelam a extensão do seu pouco caso, ela exclama desolada: ah, meu amor, eu não vi que era alguma coisa!
}

No desejo de que cada gestor consiga ver que aquilo que ele construiu no chão da escola "era alguma coisa". Alguma coisa que tocava, queimava, fazia sentir (ou fazia sentido), ainda que para uma existência mínima. No desejo que ao ver que era alguma coisa, ainda que mínima, possamos reduzir as violências. 


\section{Considerando o inconcluso ou antes ainda, um apelo}

É emergente a necessidade de se pensar e problematizar o que escolas estão produzindo nesses tempos em termos de subjetividades. Os movimentos políticos e sociais são velozes demais e acompanhar as modulações e atualizações de mecanismos de controle e regulação exige estar atento. Vivemos tempos em que políticas locais e globais são produzidas influenciadas por agendas e demandas internacionais e intergovernamentais para atender a um sistema econômico que vem apresentando sintomas de enfermidade. Tal sistema capitalista vem fazendo ruir em muitos países o que se veio construindo até agora, não sem esforços, por aquilo que se entende por práticas democráticas. Os ditames neoconservadores e neoliberais estão mudando todo o cenário de forma coextensiva a grande parte dos países do mundo.

Se antes a aposta recaía sobre a necessidade de uma gestão democrática na educação pública, hoje vemos tal aposta colapsar e entrar num campo de incertezas. Não é com tranquilidade que vemos a escola, principalmente no contexto do atual Governo Bolsonaro, ser colocada fortemente sob o crivo da crise, inflamada, principalmente, pelos discursos de doutrinamento, marxismo cultural e ideologia de gênero. Acusações que abalam a gestão escolar, que passa a ser alvo de especulações privadas ou autoritárias.

Não está mais na gestão democrática a salvação que muitos otimistas da educação acreditavam haver. A promessa de salvação é agora sustentada pelo setor privado, por fundações de amparo social e ainda, sem duras penas, por aquilo que nem adentramos neste artigo: a ameaça das escolas cívico-militares — que, a exemplo do Brasil, nos últimos três anos, passaram a ganhar muitos investimentos, tanto dos governos estaduais quanto do Governo Federal. Escolas essas das quais a gestão escolar é, sobretudo, exercida por oficiais militares demandados pela soberania. Não tão distante, a proposta de homeschooling, que antes era algo restrito aos países norte-americanos, começa a ganhar adeptos na disputa do jogo político nacional, sob a vestimenta de mais autonomia e menos ideologia no processo de aprendizagem. Aqui, incide sobre os pais a gestão do ensino, contratando profissionais conforme seus próprios interesses e necessidades. E há ainda, sem menos importância, a atuação das Igrejas (mais especificamente das evangélicas neopentecostais) no campo educacional, que entram com força e apoio da sociedade civil no debate político, com propostas de uma educação filantropa, que atenda aos interesses religiosos e ideológicos dos pais que, na grande maioria das vezes, refutam a ciência e o que se coloca no campo da igualdade de direitos a partir de princípios bíblicos ou negacionistas. 
Estamos entrando numa era pós-democrática, e se antes a gestão democrática na educação apresentava falhas e motivos para ser criticada (sempre com vistas a qualificá-la), sem sombra de dúvidas este é o momento de defendê-la e fazê-la resistir nesse contexto de ascensão de políticas autoritárias de extrema direita. O campo de produção de políticas é um campo largo de disputas. E se viemos mostrando ao longo deste artigo como essas políticas (ou dispositivos) vão atualizando a escola e a gestão e determinando condutas é porque entendemos que tais atualizações foram influenciadas por um sistema econômico, mas não sem resistência. Já dizia Foucault (2010) que em toda relação de poder há resistências. E durante muito tempo e ainda hoje se resiste. Mesmo na sociedade disciplinar em que se havia uma rígida ortopedia sobre o corpo, se resistia com movimentos de educação libertária. E se vivemos em tempos de sociedade de controle, em que muito fortemente escolas são afetadas pela lógica do mercado e da cultura performática, há gestões que buscam brechas para não sufocar a tal racionalidade capitalista. Se nossa intenção maior foi pensar uma Gestão do Cuidado como possibilidade, esta ideia, mobilizada pelo pensamento foucaultiano, não veio sem saber de que há muita Gestão do Cuidado sendo feita por ai ${ }^{\text {iv }}$. A própria Gestão Democrática pode ser, ela mesma, uma Gestão do Cuidado, uma vez que, enfatizamos, nada é tão fortemente uma coisa que não possa ser outra ao mesmo tempo, vergando e oscilando em menor ou maior intensidade de um lado a outro.

Talvez a batalha mais importante que se coloca nesses tempos é a ameaça privatizadora, com seu discurso sedutor de "qualidade total" e "liberdade de escolha". E aqui a gestão da escola pública tem papel crucial de enfrentamento na retomada do coletivo e na mobilização de práticas democráticas que envolvam toda comunidade escolar, práticas estas atravessadas pela lógica da Gestão do Cuidado que viemos traçando aqui. Se para o sujeito ser disciplinado era preciso que a disciplina passasse pelo corpo, o mesmo princípio é verdadeiro para a democracia. Não se sabe o que é democracia sem que se tenha experimentado práticas democráticas. Esse é o imperativo para que possamos caminhar na construção de uma nova racionalidade, salvo esta que está aí - neoliberal. O que não podemos é deixar-nos solapar nesse momento em que, como nunca antes, tão fortemente se exige o levante das trincheiras.

\section{Referências}

BALL, S. Profissionalismo, Gerencialismo. Performatividades e fabricações na economia educacional: rumo a uma sociedade performativa. Educação e realidade, 35(2), p. 37-55, 2010. 
Sociologia das políticas educacionais e pesquisa crítico-social: uma revisão pessoal das políticas educacionais e da pesquisa em política educacional. Tradução de Alice Casimiro Lopes e Elizabeth Macedo. Currículo sem Fronteiras, 6(2), p. 10-32, 2006.

The teacher's soul and the terrors of performativity. Journal of Education Policy. 18(2), p. 215-228, 2003.

BROWN, W. Nas ruínas do neoliberalismo: a ascensão da política antidemocrática no ocidente. Tradução de Mario A. Marino, Eduardo Altheman C. Santos. São Paulo: Editora Filosófica Politeia, 2019, 246 p.

CERVI, G. M. Política de gestão escolar na sociedade de controle. Rio de Janeiro: Achiamé, 2013.

Política de gestão escolar na sociedade de controle. 2010. 245 f. Tese (Doutorado em Ciências Sociais) - Pontifícia Universidade Católica de São Paulo, São Paulo, 2010. Disponível em: <https://tede2.pucsp.br/handle/handle/4201> Acesso em: 4 ag. 2020.

CORRÊA, M. O que pode um corpo na escola?: uma cartografia das potencialidades do corpo em espaço de escolarização. 2017. 121 f., il. Dissertação (Mestrado em Educação) Programa de Pós-Graduação em Educação, Centro de Ciências da Educação, Universidade Regional de Blumenau, Blumenau, 2017. Disponível em:

<http://www.bc.furb.br/docs/DS/2017/362383_1_1.pdf>. Acesso em: 4 ag. 2020.

DARDOT, P.; LAVAL, C. A nova razão do mundo: ensaio sobre a sociedade neoliberal. $1^{\text {a }}$ ed. Tradução de Mariana Echalar. São Paulo: Boitempo, 2016, 413 p.

DELEUZE, G. Post Scriptum sobre as sociedades de controle. In: DELEUZE, Gilles. Conversações. Tradução de Peter Pál Pelbart. São Paulo: Ed. 34, 1992, 219-226 p.

Post Scriptum sobre as sociedades de controle. In: DELEUZE, Gilles. Conversações. $3^{\mathrm{a}}$ ed. Tradução de Peter Pál Pelbart. São Paulo: Ed. 34, 2013, 214 p.

DUSSEL, I.; CARUSO, M. A invenção da sala de aula: uma genealogia das formas de ensinar. Tradução de Cristina Antunes. São Paulo: Moderna, 2003.

FOUCAULT, M. Vigiar e punir: nascimento da prisão. 42. ed. Tradução de Raquel Ramalhete. Petrópolis: Vozes, 2014.

Vigiar e punir: nascimento da prisão. 38. ed. Tradução de Raquel Ramalhete. Petrópolis: Vozes, 2010a, 291 p.

. A hermenêutica do sujeito: curso dado no Collège de France (1981-1982). $3^{\mathrm{a}}$ ed. Tradução de Márcio Alves da Fonseca, Salma Tannus Muchail. São Paulo: Editora WMF Martins Fontes, 2010b, 506 p.

O nascimento da biopolítica: curso dado no Collège de France (1978-1979).

Tradução de Eduardo Brandão. São Paulo: Martins Fontes, 2008, 474 p.

O poder psiquiátrico: curso dado no Collège de France (1973-1974). São Paulo:

Martins Fontes, 2006.

. Microfísica do poder. Tradução de Roberto Machado. Rio de Janeiro: Graal, 2003.

Revista Interinstitucional Artes de Educar. Rio de Janeiro, V.7, N.2 - pág. 1167-1183 mai-ago de 2021: "Dossiê História das Mulheres e Educação” - DOI: 10.12957/riae.2021.63459 
Em defesa da sociedade: curso dado no Collège de France (1975-1976). Tradução de Maria Ermantina Galvão. São Paulo: Martins Fontes, 1999.

A ética do cuidado de si como prática da liberdade. (entrevista com H. Becker, R. Fomet-Betancaurt, A. Gomez-Müller, em 20 de janeiro de 1984). Concórdia Revista internacional de filosofia. 6, 1984. Disponível em: < http://escolanomade.org/wpcontent/downloads/foucault_\%20etica_cuidado_si.pdf> Acesso em: 5 ag. 2020.

FREITAS, A. S. Michel Foucault e o "cuidado de si": a invenção de formas de vida resistentes na educação. ETD - Educ. Tem. Dig., Campinas, 12 (1), p. 167-190, 2010.

JUNGLOS, J. O. Tem alguma coisa acontecendo ali, e eu gosto: Uma Cartografia do Cotidiano de uma Escola Pública de Blumenau/SC. 104f, 2018. Dissertação (Mestrado em Mestrado em Educação) - Universidade Regional de Blumenau - FURB. Blumenau, SC. 2018.

LAPOUJADE, D. As existências mínimas. $1^{\mathrm{a}} \mathrm{ed}$. Tradução de Hortencia Santos Lencastre. São Paulo: N-1 Edições, 2017, 128 p.

LARROSA, J. Notas sobre a experiência e o saber de experiência. Revista Brasileira de Educação, 19, p. 20-28, 2002.

LAVAL, C. A escola não é uma empresa: o neo-liberalismo em ataque ao ensino público. Tradução de Maria Luiza M. de Carvalho e Silva. Londrina: Editora Planta, 2004, 324 p.

LOPES, A. C.; MACEDO, E. Nota introdutória: reconfigurações nos estudos sobre políticas de currículo. Currículo sem fronteiras, 6 (2), p. 5-9, 2006.

MEIRELES, C. Ou isto ou aquilo. Rio de Janeiro: Editora Nova Fronteira, 1990.

SANTOS, A. I. dos. Sob as peles, corpos: rostidades no currículo do grêmio estudantil. 133f, 2018. Dissertação (Mestrado em Mestrado em Educação) - Universidade Regional de Blumenau, FURB. Blumenau, SC. 2018.

SIBILIA, P. Redes ou paredes: a escola em tempos de dispersão. Tradução de Vera Ribeiro. Rio de Janeiro: Contraponto, 2012.

SILVA, J. C. B. Escola em tempos de democracia: capturas ou possibilidades? 131f, 2016. Dissertação (Mestrado em Educação) - Universidade Regional de Blumenau - FURB, Blumenau - SC. 2016.

SOURIAU, E. Avoir une âme - essai sur les existences virtuales. Belles-Lettres/Annales de l'université de Lyon, 1939.

VARELA, J.; ALVAREZ-URIA, F. A maquinaria escola. Teoria \& Educação, São Paulo, 6, p. 68-96, 1992.

\footnotetext{
i Accountability - termo usado por Stephen Ball, e que na língua portuguesa pode ser traduzido como responsabilidade com ética e que remete à obrigação de membros de um órgão administrativo ou representativo de prestar contas a instâncias controladoras ou a seus representados.

ii Há autores como Dardot \& Laval (2016) e Brown (2019) que analisam essa pós-democracia por meio da ascensão de políticas antidemocráticas e autoritárias no ocidente.

${ }^{\text {iii }}$ Cf. FOUCAULT, 2010b.
} 
iv O Grupo Políticas de Educação na Contemporaneidade, da Universidade Regional de Blumenau (FURB), tem buscado realizar pesquisas sobre o currículo cotidiano das escolas, dando visibilidade às práticas de Gestão Democráticas, que poderíamos chamar de uma Gestão do Cuidado. Tais pesquisas, sempre problematizadas através da perspectiva pós-critica, podem ser conferidas em SILVA, 2016; SANTOS, 2017 e JUNGLOS, 2018. 